\author{
Ilmu Pertanian (Agricultural Science) \\ Vol. 3 No. 2 August, 2018 : 90-95 \\ Available online at http://journal.ugm.ac.id/jip \\ DOI: doi.org/10.22146/ipas.33211
}

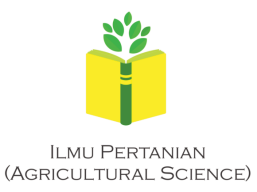

\title{
Diversity Analysis of 15 Hibiscus Accessions Based on RAPD Marker
}

\author{
Miranda Ferwita Sari* and Aziz Purwantoro \\ Faculty of Agriculture, Gadjah Mada University \\ Jl. Flora, Bulaksumur, Depok, Sleman, Yogyakarta 55281 \\ *corresponding email: mirandaferwitas@gmail.com
}

\begin{abstract}
Indonesia has many species of Hibiscus genus such as Hibiscus rosa-sinensis, kenaf, rosella, waru, sharon, and others. These species have similar flower morphology despite their different benefits. Flower morphology can be use as morphological marker characters to identify the genetic relationship in one genus of Hibiscus. However, morphological markers are less accurate because they are strongly influenced by the environment. Therefore, the molecular markers using plant DNA are considered to be more accurate than morphological characters. Random Amplified Polymorphic DNA (RAPD) analysis was applied to 15 Hibiscus genus. The result showed that 10 primers operon produced polymorphic bands. The high diversity was observed in control population i.e., H. cannabinus (K1), H. sabdariffa (K2), H. mutabilis (K3), H. syriacus (K4), H. schizopetalus (K5), while in H. rosa-sinensis, the diversity was low especially on the genotypes with the same color of flower. These results suggest that RAPD can be used to identify the diversity in plant population. The control species [H. cannabinus, H. sabdariffa, H. mutabilis, H. syriacus, and H. schizopetalus] showed high heterozygosity, suggesting high diversity were observed in these species. Based on principal coordinat analysis (PCA), two clusters were formed, the control species were clustered depend on life cycle of plant growing season either perennial or annual, while H. rosa-sinensis accessions were clustered based on the flowers color. The varian within population of $H$. rosa-sinensis accessions was higher than among population, suggesting that $H$. rosa-sinensis is cross pollinated plants due to the position of stigma is higher than anthers.
\end{abstract}

Keywords: Diversity, Hibiscus, RAPD

\section{INTRODUCTION}

Hibiscus belongs to the Malvaceae family. The Hibiscus genus is consist of 300 species with different growth characeristic ranging from small plants, shrubs, perennial crops, and annual crops spread over sub tropical and tropical area (Prasad, 2014). Hibiscus rosa-sinensis is able to grow and bloom throughout the year in both dry and rainy season, and even in a poor nutrient soil (Akpan, 2006 cit Kuligowska et al., 2016). It has great variation of morphological characters such as flower colors and sizes, and the leaf shapes. The great variation in Hibiscus rosa-sinensis was observed because of crosses and mutation (Kadve et al., 2012). Another variation is observed in the flower shape either single and double petals (Hammad, 2009). Indonesia has many species of Hibiscus genus such as $\mathrm{H}$. rosa- sinensis, kenaf, rosella, waru, sharon, etc. These species have similar flower morphology and different benefits such as traditional medicine (Pekamwar et al., 2013) or ornamental plant because of flower variation (Harvey, 2004). H. rosa-sinensis has been used for traditional medicine in India because its flower contents antioxidant, antifungal, anti-infectious, antimicrobial, anti-inflammatory, anti-diarrheic, and antipyretic compounds (Patel et al., 2012). Hibiscus consists of 300 species implying high diversity of this genera. Therefore, morphological and molecular marker can be used to reveal their phenotype and genotype diversities.

Flower morphology can be use as morphological marker characters to identify the genetic relationship in one genus of Hibiscus. However, morphological markers are less accurate because they are strongly influenced by the environment, requiring quite 
amount of time, and showing limited and inconsistent diversity (Zulfahmi, 2013). Then, molecular markers are preferable to utilize because plant DNA is stable and not affected by environmental factors. One of the most used molecular marker is Random Amplified Polymorphic DNA (RAPD). RAPD is easy and uses random primer DNA sequences as marker (Kadve et al., 2012). RAPD usually uses 10 bases short primer sequences to randomly amplify DNA genom. DNA fragmen amplification is performed using PCR machine at low annealing temperature (William et al., 1990). The DNA bands amplified from PCR can be scored to identify the genetic relationship among 15 Hibiscus genus using dendogram.

\section{MATERIALS AND METHODS}

This research was conducted in June-November 2017 at the Plant Breeding Laboratory, Agriculture Department, Faculty of Agriculture, Universitas Gadjah Mada, Yogyakarta. It used leaves of 15 Hibiscus genus consist of $H$. cannabinus (K1), H. sabdariffa (K2), H. mutabilis (K3), H. syriacus (K4), $H$. schizopetalus (K5) and H. rosa-sinensis (R1-R10). $H$. rosa-sinensis consist of 10 accessions with different flower colors i.e., red (R1-R3), white (R4-R6), yellow (R7-R8) and orange (R9-R10). Material used for DNA extraction is CTAB buffer solution, chloroform, isoamyl alcohol, sodium acetate $3 \mathrm{M}$, isopropanol, and ethanol $70 \%$.

DNA was extracted from a $0.1 \mathrm{~g}$ fresh and healthy leaf using CTAB method (Doyle and Doyle, 1990). Afterward, DNA pelette was diluted with $\mathrm{ddH}_{2} \mathrm{O}$. DNA concetration was measured with Gene Quant Spectrophotometer, then each sample of DNA was diluted with $\mathrm{ddH}_{2} \mathrm{O}$ for temperature and primer optimization in PCR reaction. Ten optimized primers were used in this research i.e., OPA 13, OPB 18, OPC 2, OPD 2, OPD 5, OPD 7, OPD 8, OPD 18, OPD 20 and OPM 6. Optimization of annealing temperature was carried out at $35^{\circ} \mathrm{C}-45^{\circ} \mathrm{C}$, then suitable temperature which produced brightest band was selected as annealing temperature.

DNA amplification was performed with PCR (Thermal Cycler BIORAD). The touchdown method was used by reducing annealing temperature from $41^{\circ} \mathrm{C}$ to $37^{\circ} \mathrm{C}$. The amplification reaction stage was $95^{\circ} \mathrm{C}$ pre-heating for $5 \mathrm{~min} ; 15$ cycles of $95^{\circ} \mathrm{C}$ denaturation for $30 \mathrm{sec}$ and specific annealing temperature for $30 \mathrm{sec} ; 72^{\circ} \mathrm{C}$ elongation for $90 \mathrm{sec}$; and $72^{\circ} \mathrm{C}$ final elongation for $7 \mathrm{~min}$.

Gel electrophoresis was performed in 100 volts for $55 \mathrm{~min}$ using $1 \%$ agarose gel in TBE buffer, visualized using UV light, and the image was captured with a digital camera. The bands were scored to form a binary data, $1=$ the band was amplified, and $0=$ no band.

The data was analyzed using Sequential, Agglomerative, Hierarchical, and Nested (SAHN) with Unweight pair-group method, arithmetic average (UPGMA) method for cluster analysis, in NTSYS-PC version 2.02 programs. Principal Coordinate Analysis (PCA) was performed using the same program, to illustrate the distribution of 15 Hibiscus genera. The number of specific alleles in each population, analysis of molecular variance (AMOVA), heterozygosity $(\mathrm{H})$, the number of observed alleles $(\mathrm{Na})$, and the number of effective alleles $(\mathrm{Ne})$ were analyzed with GenAlEx 6.1. The specific alleles was determined by the appearance of a specific band in one specific population and that was not found in other populations. Analysis of molecular variance was used to explain the distribution and magnitude of genetic diversity in and/or between populations.

\section{RESULTS AND DISCUSSION}

H. rosa-sinensisis, one of the species in Hibiscus genus, the most common species found in Indonesia. Because of its flower variation, it was used as an ornamental and fence plant. Therefore, the purpose of this study was proposed to identify the diversity and genetic relationship of 15 Hibiscus genus. All of the species showed high diversity of flower morphologies as shown in figure 1. The variation of flower shapes was observed either within H. rosasinensis accessions or among other Hibiscus species

Hibiscus genus consists of annual crops group such as $H$. cannabinus (K1) and $H$. sabdariffa (K2), and perennial crops group such as H.mutabilis (K3), H. syriacus (K4), H. schizopetalus (K5) and H. rosa-sinensis (R1-R10). H. rosa-sinensis accessions was separated by the flower color i.e., red flower (R1-R3), white flower (R4-R6), yellow flower (R7R8), and orange flower (R9-R10). All Hibiscus genera were generally had similar utility for ornamental, medicinal, and fiber source plants. Genetic relationship analysis was performed in accordance to the similarity of morphology, lifespan, and utility among several types of Hibiscus. Five from ten primers showed 100\% of polymorphic bands (Table 1). OPB 18, OPD 7, OPD 18, OPD 20, and OPM 6 showed 100\% of polymorphic bands suggesting that 15 Hibiscus genera had high diversity.

Genetic relationship of 15 Hibiscus genera using 10 RAPD primers was identified by dendogram 


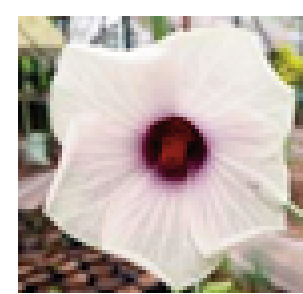

K1

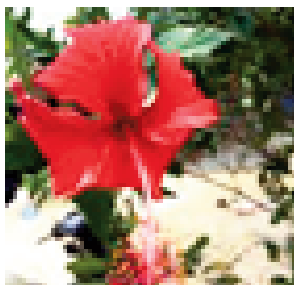

R1

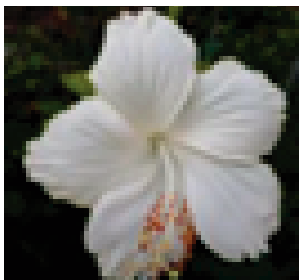

R6

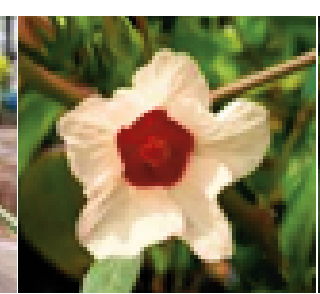

K2

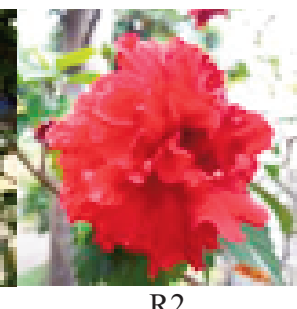

R2

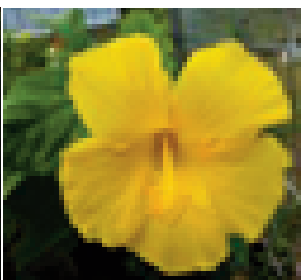

R7

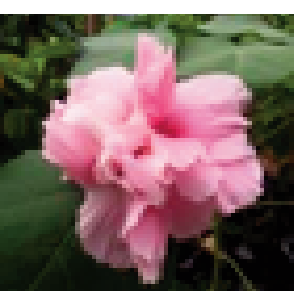

K3

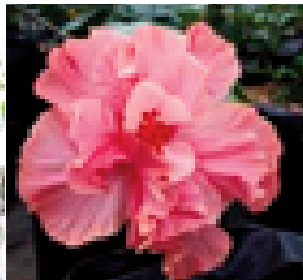

R3

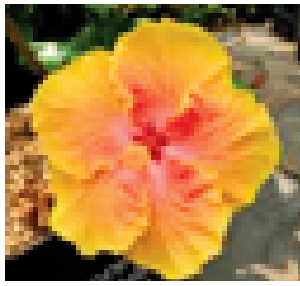

R8

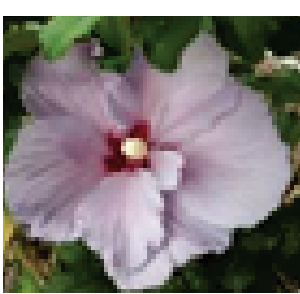

K4

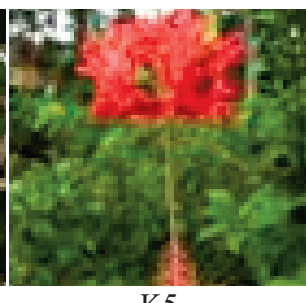

K5
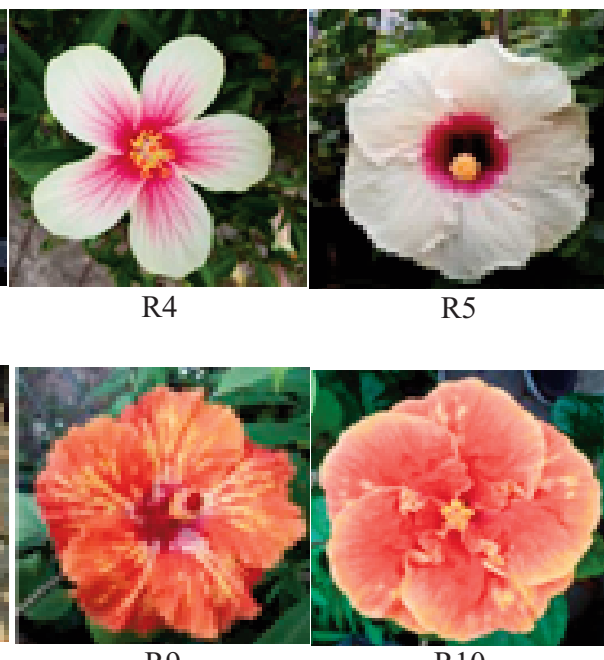

R9

Figure 1. 15 genus hibiscus diversity

Note: K1 : H. cannabinus, K2 : H. sabdariffa, K3 : H. mutabilis, K4 : H. syriacus, K5 : H. schizopetalus, R1-R10: H. rosa-sinensis

Table 1. Polymorphic Bands 15 Hibiscus Genus in 10 Primer RAPD

\begin{tabular}{lccccc}
\hline Primer & Total No. of bands & $\begin{array}{c}\text { Total No. of } \\
\text { polymorphic bands }\end{array}$ & $\begin{array}{c}\text { Total No. of } \\
\text { monomorphic bands }\end{array}$ & Polymorphism (\%) & Monomorphism (\%) \\
\hline OPA 13 & 15 & 14 & 1 & 93.33 & 6.67 \\
OPB 18 & 21 & 21 & 0 & 100 & 0 \\
OPC 2 & 19 & 18 & 1 & 94.74 & 5.26 \\
OPD 2 & 16 & 14 & 2 & 87.5 & 12.5 \\
OPD 5 & 13 & 12 & 1 & 92.31 & 7.69 \\
OPD 7 & 17 & 17 & 0 & 100 & 0 \\
OPD 8 & 17 & 16 & 1 & 94.12 & 0 \\
OPD 18 & 21 & 21 & 0 & 100 & 0 \\
OPD 20 & 19 & 19 & 0 & 100 & 0 \\
OPM 6 & 17 & 17 & 0 & 96.8 & 3.8 \\
\hline Total & 175 & 169 & 6 & & 0 \\
\hline
\end{tabular}

(Fig. 2). The result showed that the genetic relationship coefficient was 0.78 (the closest) and 0.36 (the farthest). R9 and R10 were the two most similar genotypes, due to their genetic relationship coefficient (0.78) and their similar phenotype appearances. Dendogram categorized 15 genotypes into two main groups. The first group consisted of H. cannabinus (K1), H.sabdariffa (K2), and H. mutabilis (K3); the second group consisted of $H$. syriacus (K4), $H$. schizopetalus (K5) and H.rosa-sinensis (R1-R10). In the first group (A), K1 was separated from K2 and
$\mathrm{K} 3$ with 0.42 similarity coefficient, while $\mathrm{K} 2$ and $\mathrm{K} 3$ had similarity coefficient (0.47). The second group was categorized into two smaller groups, B1 and B2. B1 group consisted of 2 genotypes, $\mathrm{K} 4$ and R6, with 0.41 similarity coefficient, and B2 group was categorized into two groups, B.2.1 and B.2.2, where $\mathrm{K} 5$ was separated from the other 9 genotypes with the similarity coefficient is 0.43 . B.2.2 group was categorized into two small groups, B.2.2.1 and B.2.2.2. B.2.2.1 consisted of three $\mathrm{R} 1$ genotypes with 0.63 similarity coefficient, and separated from 


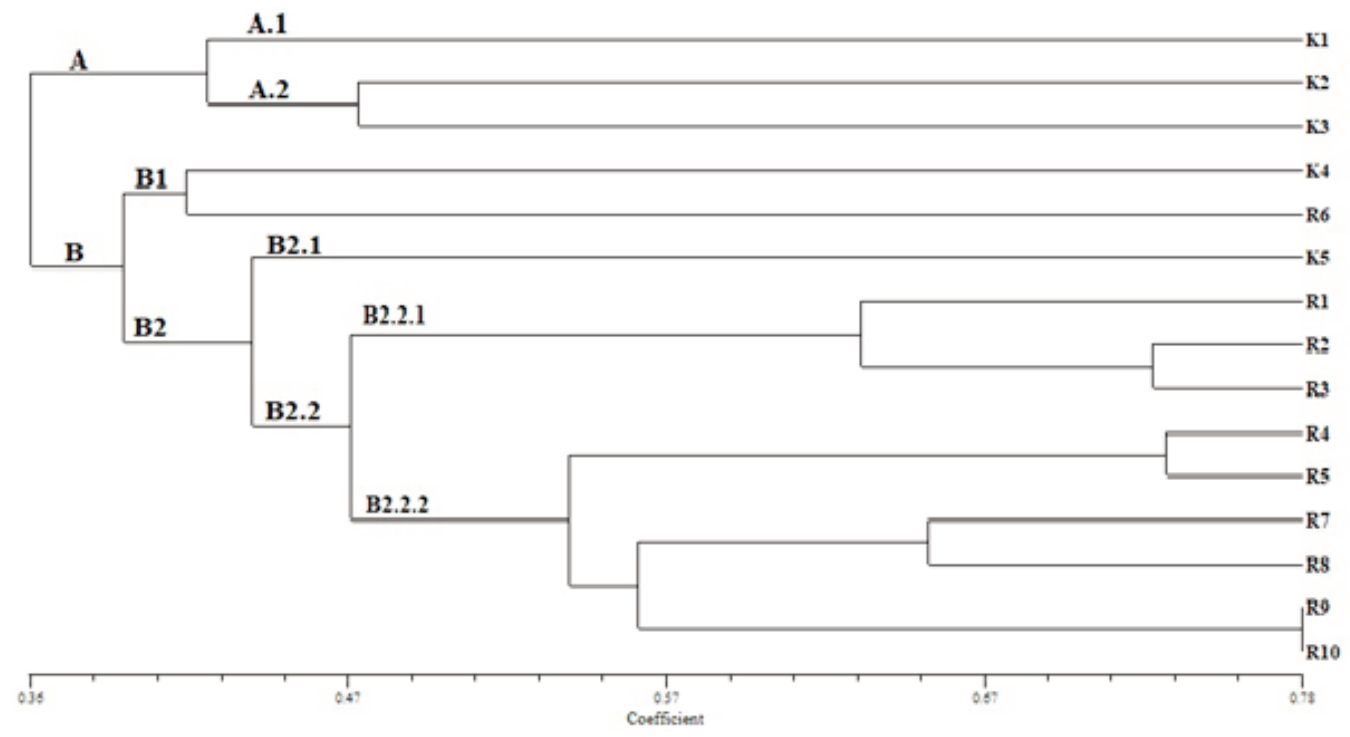

Figure 2. Dendogram Diversity Analysis using RAPD Marker

R2 and R3 genotypes with the similarity coefficient was 0.72. Then B.2.2.2 consisted of 6 genotypes where R9 and R10 have the closest genetic relationship (similarity coefficient 0.78 ) compared with other genotypes (R7 and R8 with similarity coefficient 0.65 , and R4 and R5 with similarity coefficient 0.73 ). H. rosa-sinensis group was tend to gather, separated from the other Hibiscus species.

Generally, the 15 Hibiscus accessions were grouped based on their population. The PCA result showed that all Hibiscus species were organized according to the flowers color (Fig. 3). Populations of the red H. rosa-sinensis are gathered into one group, as well as the orange one. While on the yellow, white, and control group, there were separated from those genotypes. K4 and K5, the perennial crops, were separated from $\mathrm{K} 1$ and $\mathrm{K} 2$, the annual crops. However, the white and yellow $H$. rosa-sinensis species were assembled in one group. These results suggest that all of 15 Hibiscus accessions were assembled in accordance with their flower colors.

Several variables such as observed alleles, effective alleles, heterozygosity, and Shannon index, were used to evaluate genetic diversity in a population (Pereira et al., 2015) and calculated from the three population's data (Table 2). Heterozygosity values of each population was 0.21 (control), 0.13 (red H. rosasinensis), 0.15 (white $H$. rosa-sinensis), 0.1 (yellow $H$. rosa-sinensis), and 0.06 (orange $H$. rosa-sinensis). These results suggest that the control group, consist of $H$. cannabinus, $H$. sabdariffa, $H$. mutabilis, $H$. syriacus and $H$. schizopetalus had the highest genetic diversity, whereas the orange group had the lowest genetic diversity. The observed allele value $(\mathrm{Na})$ and Shannon Index (I) analysis, control group and orange group were exhibited the highest and the lowest genetic diversity, respectively. Effective allele value $(\mathrm{Ne})$ is usually smaller than $\mathrm{Na}$ value in control population because the population consist of different kinds of Hibiscus species. However, in other population, $\mathrm{Ne}$

Principal Coordinates

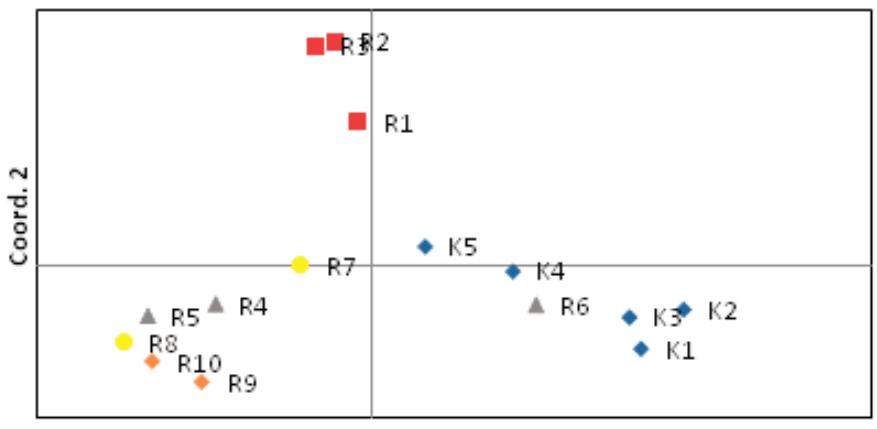

Coord. 1

$$
\begin{aligned}
& \text { - kontrol } \\
& \text { - red-group } \\
& \text { A white-group } \\
& \text { - vellow-group } \\
& \text { - orange-group }
\end{aligned}
$$

Figure 3. PCA Result of 15 Hibiscus Accessions 
Table 2. Average of observed allele (Na), Effective allele value (Ne), Shannon Index (I) and heterozigosity $(\mathrm{h})$

\begin{tabular}{lccccc}
\hline \multicolumn{1}{c}{ Population } & $\mathrm{N}$ & $\mathrm{Na}$ & $\mathrm{Ne}$ & $\mathrm{I}$ & $\mathrm{H}$ \\
\hline Control & 5 & $1.49 \pm 0.064$ & $1.31 \pm 0.021$ & $0.33 \pm 0.017$ & $0.21 \pm 0.012$ \\
Red-group & 3 & $0.82 \pm 0.068$ & $1.22 \pm 0.027$ & $0.19 \pm 0.021$ & $0.13 \pm 0.014$ \\
White-group & 3 & $0.92 \pm 0.072$ & $1.25 \pm 0.026$ & $0.23 \pm 0.021$ & $0.15 \pm 0.014$ \\
Yellow-group & 2 & $0.74 \pm 0.063$ & $1.18 \pm 0.023$ & $0.15 \pm 0.020$ & $0.1 \pm 0.014$ \\
Orange-group & 2 & $0.56 \pm 0.056$ & $1.11 \pm 0.019$ & $0.09 \pm 0.016$ & $0.06 \pm 0.011$ \\
\hline Average & 3 & $0.91 \pm 0.031$ & $1.21 \pm 0.011$ & $0.20 \pm 0.009$ & $0.13 \pm 0.006$ \\
\hline
\end{tabular}

Table 3. AMOVA

\begin{tabular}{lccccc}
\hline \multicolumn{1}{c}{ Source } & df & Sum Square (SS) & Mean Square (MS) & Est. variance & Variance $(\%)$ \\
\hline Among Populations & 4 & 226.80 & 56.7 & 8.69 & 22 \\
Within Populations & 10 & 315.07 & 31.51 & 31.51 & 78 \\
\hline Total & 14 & 541.87 & & 40.19 & 100 \\
\hline
\end{tabular}

value is bigger than $\mathrm{Na}$ because of the random mating was occurred in H. rosa-sinensis, and it was a cross pollinated plant.

Table 3 showed the value of genetic diversity within and between populations. Diversity value between different flowers of $H$. rosa-sinensis flower was varied. AMOVA showed the same pattern of genetic diversity within and between populations and it was used to identify the distribution of genetic diversity within and between populations. AMOVA result (Table 3) showed that $78 \%$ of the total genetic diversity was diversed within genotype population, while the rest was diversed between populations. Distribution patterns of genetic diversity, as well as the percentage of diversity within population, was higher than between populations, which commonly found in cross-pollinated plants.

Genetic diversity within population is resulted from its sexual reproduction (Pereira et al., 2015). Then, the great diversity found in the cross pollinated crops was caused random mating. Meanwhile, population diversity is the average of genetic diversity from entire genotypes within the population. In cross-pollinated plants, although the genotypes generating each population vary, diversity value between one population and the other tend to be small, so the diversity between populations is small. This is in accordance with Hamrick et al. (1992), that wood species with cross-breeding system and seed dispersal caused by wind or animal will maintain more variation within species and population than other species, but the diversity between populations is smaller.

\section{CONCLUSIONS}

The molecular marker is a good marker to reveal the diversity in a population. Highest heterozygosity value in control group genotypes showed that there was a high diversity in control plants. Based on dendogram result, $H$. rosa-sinensis had a close genetic relationship with $H$. schizopetalus. Based on the PCA result, the grouping in control plants was assembled according to their growth cycles (perrenial and annual), while in $H$. rosa-sinensis the grouping was based on the flowers color. H. rosa-sinensis is cross pollinated plants because the stigma position is higher than anthers, and the varians within population of $H$. rosa-sinensis was higher than among population.

\section{ACKNOWLEDGEMENT}

The authors express deep gratitude to the Faculty of Agriculture, University of Gadjah Mada, Yogyakarta for the funding provided for this research.

\section{REFERENCES}

Akpan, G.A. 2006. Hibiscus. In: Anderson, N.O. (ed.) Flower Breeding and Genetics: Issues, Challenges and Opportunities for the 21st Century. Springer, Dordrecht.

Hammad, Ibtisam. 2009. Genetic variation among Hibiscus rosa-sinensis(Malvaceae) of different flower colors using Issr and Isozymes. Australian Journal of Basic and Applied Sciences 3(1): $113-125$.

Hamrick J.L., M.J.W. Godt\& S.L. Sherman-Broyles. 1992. Factors influencing levels of genetic diversity in woody plant species. New Forests $6: 95-124$. 
Harvey, Geoff. 2004. Hibiscus Hybridization guide Part 3: Applied genetic. http://www.international hibiscus society.org/HI17 file/hiv1n171-2.html.

Kadve, S., M. Yadav and A. Tiwari. 2012. Genetic analysis on hibiscus species by using RAPD markers. International Journal of Biomedical and Advance Research 3(6): 473-485.

Kuligowska, K., H. Lutken, B. Christensen and R. Muller. 2016. Interspecific hybridization among cultivars of hardy Hibiscus species section Muenchhusia. Breeding Science 66: 300-308.

Patel, R., A. Patel, D. Vaghasiya, and A. Nagee. 2012. Elucidation of genetic diversity among five cultivars of Hibiscus rosa-sinensisusing single primer amplification reaction (Spar). IOSR Journal of Pharmacy and Biological Sciences 1: 15-19.

Pekamwar, S.S., T.M. Kalyankar and A.C. Jadhav. 2013. Hibiscus rosa-sinensis: a review in ornamental plant. World Journal of Pharmacy and Pharmaceutical Science 2(6): 4719-4727.
Pereira D.A., R.X. Correa \& A.C. Oliveira. 2015. Molecular genetic diversity and differentiation of populations of 'somnus' passion fruit trees (Passiflorasetacea DC) : implications for conservation and pre-breeding. Biochemical Systematics and Ecology $59: 12-21$.

Prasad M.P. 2014. Molecular characterization and genetic diversity determination of Hibiscus species using RAPD molecular markers. Asian Journal of Plant Science and Research 4(3): 50-56.

William, J.G.K., A.R. Kubelik, K.J. Livak, J.A. Rafalski, and S.V. Tingey. 1990. DNA Polymorphism Amplified by arbitrary Primers are useful as genetic marker. Nucleic Acids Research 18: 6531-6535.

Zulfahmi.2013. Penanda DNA untuk analisisgenetik tanaman. JurnalAgroteknologi 3(2): 41-52. 